\title{
Variability of Optical Depth and Effective Radius in Marine Stratocumulus Clouds
}

\author{
M. SZCZODRAK \\ Rosenstiel School of Marine and Atmospheric Science, University of Miami, Miami, Florida \\ P. H. Austin \\ Atmospheric Sciences Programme, University of British Columbia, Vancouver, British Columbia, Canada \\ P. B. KRUMMEL \\ CSIRO Atmospheric Research, Aspendale, Victoria, Australia
}

(Manuscript received 31 January 2000, in final form 12 March 2001)

\begin{abstract}
Radiance measurements made by the Advanced Very High Resolution Radiometer (AVHRR) at 1-km (nadir) spatial resolution were used to retrieve cloud optical depth $(\tau)$ and cloud droplet effective radius $\left(r_{\text {eff }}\right)$ for 31 marine boundary layer clouds over the eastern Pacific Ocean and the Southern Ocean near Tasmania.

In the majority of these scenes (each roughly $256 \times 256 \mathrm{~km}^{2}$ in extent) $\tau$ and $r_{\text {eff }}$ are strongly correlated, with linear least squares yielding a regression curve of the form $r_{\text {eff }} \propto \tau^{1 / 5}$. This relationship is consistent with an idealized model of a nonprecipitating layer cloud in which 1) the average cloud liquid water content increases linearly with height at some fraction of the adiabatic lapse rate in a $1 \mathrm{~km}^{2}$ vertical column, and 2) the normalized horizontal variability of the cloud liquid water path exceeds the variability of a scaled measure of the cloud droplet number concentration. In contrast, other scenes of similar horizontal extent show little or no correlation between retrieved values of $\tau$ and $r_{\text {eff }}$. These scenes include thicker clouds in which precipitation may be occurring, as well as cloud layers with spatially distinct regions of varying $r_{\text {eff }}$.

In situ aircraft measurements were made simultaneously with six AVHRR overpasses as part of the Southern Ocean Cloud Experiment. The clouds sampled by these flights were significantly thicker than the typically 200m-thick eastern Pacific stratocumulus, with large vertical and horizontal variability. On five of the six flights, aircraft measurements of the cloud-top effective radius were well matched by the satellite retrievals, and in two of these layers $r_{\text {eff }} \propto \tau^{1 / 5}$.
\end{abstract}

\section{Introduction}

Marine stratus and stratocumulus clouds play a significant role in the planetary energy budget. Globally, boundary layer clouds act to decrease the net radiative forcing by $15 \mathrm{~W} \mathrm{~m}^{-2}$ due to their large reflectivity (Hartmann et al. 1992). This reflectivity varies with cloud parameters such as cloud fraction, column-integrated liquid water, and the mean surface area of cloud droplets. Knowledge of the seasonal and spatial variability of these cloud parameters is a prerequisite for understanding feedbacks between boundary layer cloud properties and natural or anthropogenic climate change.

Efforts to incorporate prognostic equations for cloud liquid water content and sulphate mass in global climate models have underscored the uncertainties inherent in

Corresponding author address: Dr. Philip H. Austin, Atmospheric Science Programme, University of British Columbia, 6339 Stores Road, Vancouver, BC V6T 1Z4, Canada.

E-mail: paustin@eos.ubc.ca predicting the impact of aerosol concentration on cloud reflectivity (Lohmann and Feichter 1997). At the same time, a new generation of cloud-resolving models, run with horizontal and vertical resolutions of tens of meters and domain sizes of kilometers, are making detailed predictions about the distribution of fluctuations in cloud liquid water and cloud droplet size. To better constrain predictions at both ends of the modeling spectrum, observations of cloud liquid water path, particle size, and droplet number concentration across a range of scales are needed.

Several recent studies have shown that satellite-based passive remote sensing can provide information on the cloud optical depth $\tau$ (related to the extinction of the direct solar beam), the surface area-weighted mean radius $r_{\text {eff }}$ (or effective radius; see appendix A for definitions), the liquid water path (lwp), and a measure of the droplet number concentration in the column (see, e.g., Han et al. 1994; Nakajima and Nakajima 1995; Platnick and Valero 1995; Han et al. 1995, 1998a; Greenwald and Christopher 1999; Han et al. 1998b). 
TABLE 1. The grid system for values of cloud base $(z)$, cloud thickness $(\Delta z)$, solar zenith angle $\left(\theta_{0}\right)$, satellite zenith angle $(\theta)$, optical depth $(\tau)$, and effective radius $\left(r_{\text {eff }}\right)$ for the lookup tables used for the satellite $\tau, r_{\text {eff }}$ retrievals.

\begin{tabular}{ll}
\hline \hline Quantity & \multicolumn{1}{c}{ Grid points } \\
\hline$z(\mathrm{~km})$ & $1.0,1.5,2.0,2.5,3.0,3.5,4.0$ \\
$\Delta z(\mathrm{~km})$ & $0.1,0.2,0.5,1.0,2.0$ \\
$\theta_{0}\left({ }^{\circ}\right)$ & $0,5,10,20,30,35,40,45,50,55,60,65,70$ \\
$\theta\left(^{\circ}\right)$ & $0,5,10,20,30,35,40,45,50,55,60$ \\
$\phi\left(^{\circ}\right)$ & $0-180($ every 10 $)$ \\
$\tau$ & $1,2,4,6,8,10,12,14,16,18,20,22,24,26,28,30,32,34,50,70$ \\
$r_{\text {eff }}(\mu \mathrm{m})$ & $4,6,8,10,12,14,16,18,20,22,24,30$ \\
\hline
\end{tabular}

Below we use the algorithm of Nakajima and Nakajima (1995) to retrieve $\tau$ and cloud-top $r_{\text {eff }}$ from 25 relatively shallow stratocumulus cloud layers located off the California coast and six deeper and more variable layers over the Southern Ocean. These scenes are representative of a larger set of 404 retrievals that we have done on 63 days of satellite data. In this paper we describe the distributions of optical depth and effective radius and their correlations, and propose a simple cloud model to account for the correlations between $\tau$ and $r_{\text {eff }}$ observed in 19 of the 31 cloud layers.

In section 2 we briefly review the Nakajima and Nakajima (1995) algorithm and discuss the uncertainties in the retrievals of $\tau$ and $r_{\text {eff }}$, while in section 3 we describe the datasets used in this paper. In section 4 we present the resulting retrievals for thin and thick clouds, with joint probability densities and mean layer statistics. In section $4 \mathrm{~b}$ we use in situ aircraft measurements to validate $r_{\text {eff }}$ retrievals in thicker clouds. Section 5 contains a summary and discussion of the results.

\section{Retrieval algorithm and uncertainties}

\section{a. Retrieval algorithm}

We use the algorithm of Nakajima and Nakajima (1995) to retrieve cloud optical depth and cloud droplet effective radius given radiance measurements in Advanced Very High Resolution Radiometer (AVHRR) channels 1 (centered at $0.63 \mu \mathrm{m}$ ), 3 (centered at 3.74 $\mu \mathrm{m}$ ), and 4 (centered at $10.8 \mu \mathrm{m}$ ). The algorithm first calculates model radiances in the same wavelength range as AVHRR channels 1 and 3 given a three layer atmosphere with specified cloud-base height, cloud thickness, visible optical depth, and droplet effective radius. The absorption coefficient for the overlying atmosphere is specified using LOWTRAN-7, with temperature and vapor soundings taken from the midlatitude summer profile (Kneizys et al. 1988). The satellite-measured radiances are then used to choose the best-fit set of model parameters, minimizing the difference between observed and model radiances while iteratively correcting for the emitted radiation in channel 3 , as described in Nakajima and Nakajima (1995). The parameter set used in the model and the view and solar zenith angles included in the calculation are listed in Table 1.

\section{b. Retrieval error estimates}

Uncertainty in the retrieved values of cloud optical depth and cloud droplet effective radius arises from three sources of error.

1) Approximation error: the error introduced by assumptions made in the forward radiative transfer model, including the assumption of a vertically uniform profile of $r_{\text {eff }}$ with height and of climatological vapor and temperature profiles. Nakajima et al. (1991) used radiances calculated from simulated clouds for which $r_{\text {eff }}$ increased linearly with height to test their $\tau, r_{\text {eff }}$ retrieval and found the retrieved $r_{\text {eff }}$ to be roughly $10 \%$ less than the cloud-top $r_{\text {eff }}$ of the vertically inhomgeneous cloud. The same retrieval overestimated $\tau$ by $1 \%-5 \%$, with uncertainty in the atmospheric water vapor profile adding 1\%-3\% to the $\tau$ and $r_{\text {eff }}$ uncertainties. Recently Brenguier et al. (2000) performed a similar calculation with a range of cloud profiles and found their retrieved $r_{\text {eff }}$ to decrease from between $100 \%$ to $80 \%$ of the modeled cloud-top value as the cloud-top $r_{\text {eff }}$ is increased from 6 to $18 \mu \mathrm{m}$.

2) Independent pixel approximation (IPA) error: this error is introduced by neglecting the horizontal radiative transfer between pixels. For overcast scenes, Chambers et al. (1997) estimate that this error for the retrieval of $\tau$ can range between $10 \%$ for $30-\mathrm{m}$ Landsat pixels to less then $5 \%$ for $5.7-\mathrm{km}$ pixels at a solar zenith angle of $63^{\circ}$. As Table B1 indicates, solar zenith angles for the AVHRR scenes were generally between $50^{\circ}$ and $60^{\circ}$, with satellite view angles typically less than $30^{\circ}$. Given the 1-km AVHRR nadir pixel size we anticipate that the IPA error should fall within this range of values. The IPA introduces a negative bias in retrievals of $\tau$. The effect of the IPA on $r_{\text {eff }}$ has not been investigated for cloud retrievals, but we anticpate that smaller channel 3 radiances due to inhomgeneous clouds would result in larger values of retrieved $r_{\text {eff }}$. The Southern Ocean clouds, which were more irregular and had lower cloud fractions, may suffer from larger IPA errors.

3) Measurements (retrieval) error: this is dominated by the uncertainty of sensor calibration and digitization, estimated for $\tau$ at about $15 \%$ for our range of $\tau$ and solar angle values (Pincus et al. 1995). The AVHRR 
channel 1 radiance measurements for the five satellites were calibrated following Kaufman and Holben (1993).

Both Han et al. (1994) and Platnick and Valero (1995) also considered the errors listed above. Platnick and Valero (1995) estimated the worse-case net uncertainty in an AVHRR retrieval of $r_{\text {eff }}$ to be $\pm 20 \%$, accounting for the channel 3 measurement error, an unknown incloud water vapor absorption and droplet size distribution uncertainties. Han et al. (1994) similarly estimated retrieval errors for their study to be between 1 and $2 \mu \mathrm{m}$. This is in agreement with validation results using collocated aircraft measurements. Nakajima and Nakajima (1995) and Platnick and Valero (1995) showed differences between satellite and in situ estimates of the effective radius differ by roughly $10 \%$, with good qualitative agreement in regions of varying $r_{\text {eff }}$. In a set of comparisons with a ground-based microwave radiometer and a pyranometer, satellite retrievals of $r_{\text {eff }}$ and liquid water path lwp by Han et al. (1995) show lwp agreement within $\approx 20 \%$ and $r_{\text {eff }}$ agreement to within approximately $10 \%$.

\section{Data}

We have selected 25 scenes of $1 \mathrm{~km} \times 1 \mathrm{~km}$ local area coverage AVHRR data with dimensions of approximately $256 \mathrm{~km} \times 256 \mathrm{~km}$ that are representative of a set of roughly 400 similarly sized retrievals, drawn from 67 different orbital swaths. The 1987 data were archived as part of the First International Satellite Cloud Climatology Program (ISCCP) Regional Experiment (FIRE) (July 1987), while data from June and July 1994 and 1995 were archived and processed at the University of British Columbia. The location for these scenes is shown in Fig. 1 and Table B1; we will also discuss six Southern Hemisphere summer scenes from the Southern Ocean near Tasmania, acquired during the Southern Ocean Cloud Experiment II (SOCEX II, February 1995; see Table B2).

For each scene, completely overcast and clear pixels are identified using the spatial coherence analysis technique of Coakley and Bretherton (1982). We limited our retrievals to the cloudy pixels for which the standard deviation of $2 \times 2$ arrays of the AVHRR channel 4 brightness temperature was below 0.5. For the northeastern Pacific scenes the fraction of cloudy pixels meeting this threshold exceeds $80 \%$; for the more variable Southern Ocean scenes the fully cloudy fraction falls to between $30 \%$ and $50 \%$. Failure to exclude pixels with larger spatial variances results in the retrieval of anomalously large droplets. This is due to a combination of two effects: 1) lower reflectivity due to cloud inhomogeneity and 2) an overestimate of the channel 3 thermal emission due to sea surface contamination of the pixel. When the erroneous thermal emission is subtracted from the channel 3 radiance, the resulting low re-

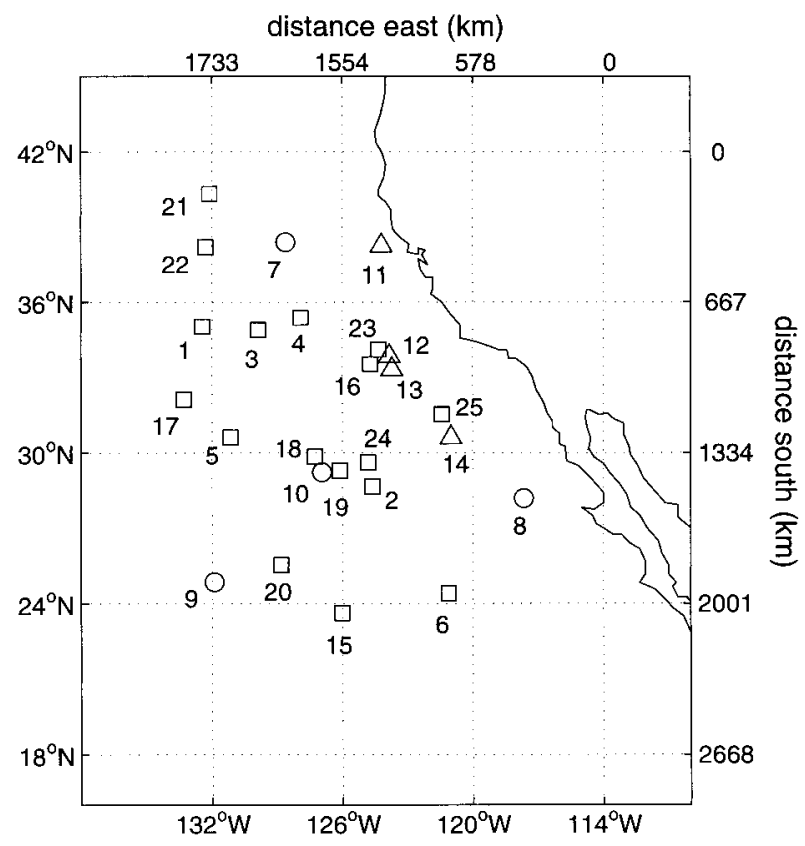

FIG. 1. The geographical location of 25 northeastern Pacific scenes used in section 4. Markers used for each scene are explained in more detail in section 4. $\square$ : scenes where for which $\tau \propto r_{\text {eff }}$; ○: scenes with bimodal distribution of $N_{\text {sat }}$ (see section 4 for the definition); $\triangle$ : scenes with thick clouds.

flectivity produces a mistaken estimate of larger cloud droplets.

\section{Results}

\section{a. Distributions of optical depth and effective radius}

Figure 2 shows $\log -\log$ contour plots of $r_{\text {eff }}$ versus $\tau$ for scenes 1, 4, 5, and 24 of Fig. 1. Shown in the figure is a mean regression line (solid) of the form

$$
\log \left(r_{\text {eff }}\right)=b \log (\tau)+a .
$$

The mean regression coefficients $b$ and $a$ for each 256 $\times 256$ pixel scene are found by averaging 100 individual regressions of sets of independent pixels, subsampled to remove spatial correlation. We determine the correlation length for the $\tau$ and $r_{\text {eff }}$ fields using the twodimensional semivariogram (second-order structure function):

$$
S_{2}(\Delta \mathbf{x})=\left\langle[\tau(\mathbf{x}+\Delta \mathbf{x})-\tau(\mathbf{x})]^{2}\right\rangle,
$$

where $\Delta \mathbf{x}$ is the $(x, y)$ separation vector between two pixels, and \langle\rangle represents an average over all pixels separated by $\Delta \mathbf{x}$.

The autocorrelation length scale for the scene is then taken as the distance over which $S_{2}$ reaches its maximum; typically this is 7-10 km for both the $\tau$ and $r_{\text {eff }}$ fields (Isaaks and Srivastava 1989; Szczodrak 1998). The random subsets are selected with pixels separated by the autocorrelation length, and a linear regression is then performed on each of these subsets of roughly 300 

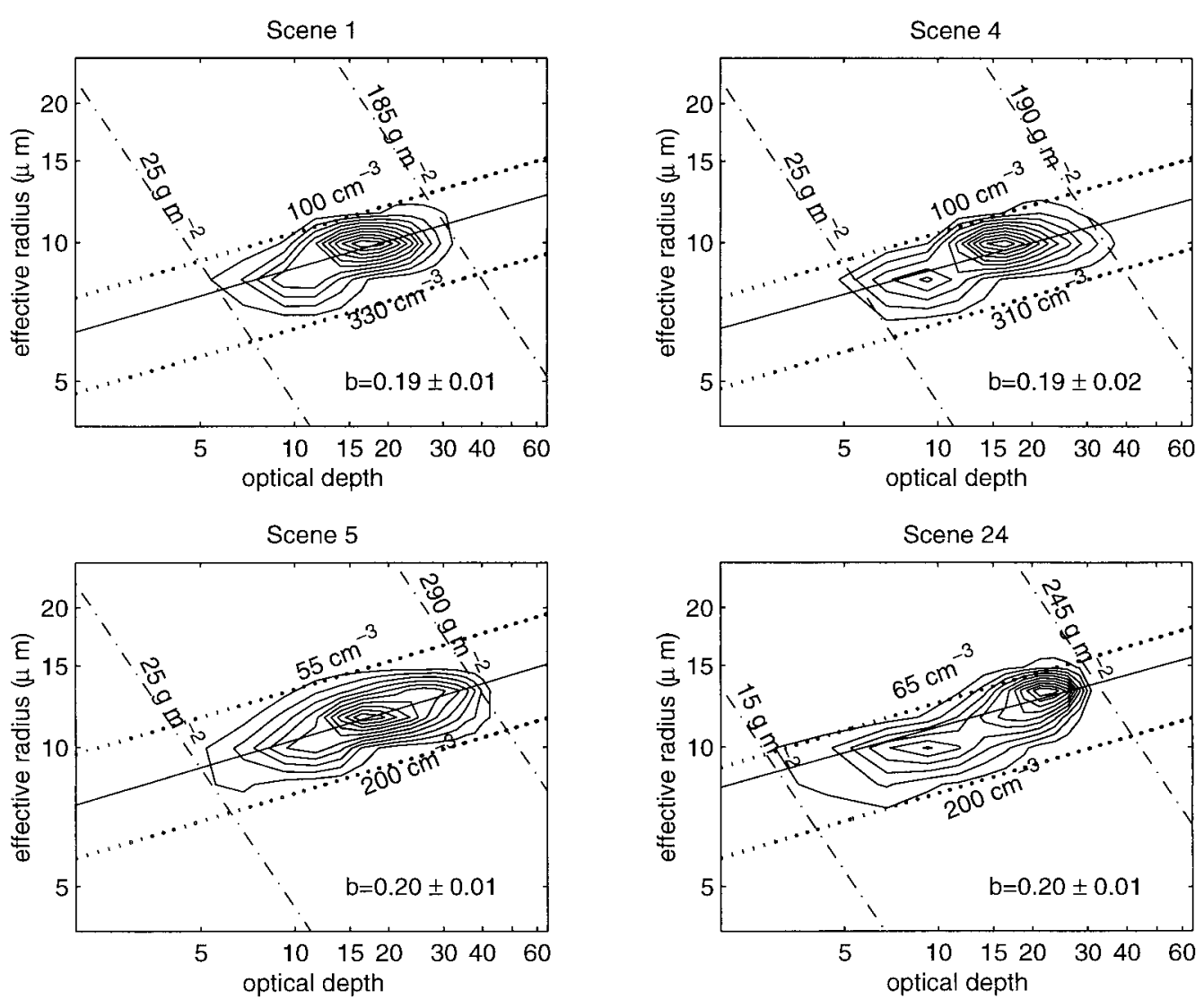

FIG. 2. $\log -\log$ contour plots of $r_{\text {eff }}$ and $\tau$ from four cloudy scenes. The contours are of the frequency density $\eta$, where $\eta \Delta \log \tau \Delta \log r_{\text {eff }}$ denotes the number of pixels with optical depth and effective radii in the range $(\log \tau$ $\left.<\log \tau^{\prime}<\log \tau+\Delta \log \tau ; \log r_{\text {eff }}<\log r_{\text {eff }}^{\prime}<\log r_{\text {eff }}+\Delta \log r_{\text {eff }}\right)$. The dot-dashed, labeled lines are isolines of lwp given by (3c); the dotted labeled lines are isolines of $N_{\text {sat }}$ given by (3b). Also shown on each panel is the linear least squares regression line (solid), with the slope $b$ and its uncertainty. Clouds with both high $\left(\tau, r_{\text {eff }}\right)$ correlations and $b \approx 0.2$ are denoted by a $\square$ in Fig. 1 .

pixels yielding the individual regression coefficients that are averged. Subsampling in this way minimizes the effect of local spatial correlations on the fit, so that the resulting correlation reflects scenewide behavior. The resulting mean slope and intercept $a$ and $b$ with uncertainties are shown in Fig. 2. We also calculate the Pearson's linear correlation coefficient for each subsampled fit, assuming uncorrelated errors of $15 \%$ for $\tau$ and $20 \%$ for $r_{\text {eff }}$ as discussed in section $2 \mathrm{~b}$. The correction for the bias introduced into the regression by the log-log transformation is negligible for these scenes (Jansson 1985).

As the solid line in each of the four panels of Fig. 2 indicates, the $\tau, r_{\text {eff }}$ scatterplots in each of these four panels are well fit by a relationship of the form $r_{\text {eff }} \propto$ $\tau^{1 / 5}$. This is also true of 13 other scenes of the 25 shown in Fig. 1 (marked with square boxes), which all yield mean $\log -\log$ regression slopes $b=1 / 5$ within the sampling uncertainty, with correlation coefficients greater than $70 \%$. Of the 404 images analyzed for this region, $40 \%$ satisfy these two the criteria.

In appendix A we review relationships between the optical depth $\tau$, the effective radius at cloud top $r_{\text {eff }}$, the liquid water path lwp, and the number concentration $N$ that hold for an idealized layer cloud in which cloud liquid water content (lwc) increases linearly with height and cloud droplet number concentration $N$ is constant with height:

$$
\begin{aligned}
r_{\text {eff }} & =a_{1}^{1 / 5} N_{\text {sat }}^{-2 / 5} \tau^{1 / 5} \\
N_{\text {sat }} & =a_{1}^{1 / 2} \tau^{1 / 2} r_{\text {eff }}^{-5 / 2} \approx k N / \sqrt{\beta}, \\
\text { lwp } & =a_{0} \tau r_{\text {eff }} .
\end{aligned}
$$

The definitions for the coefficients $a_{0}$ and $a_{1}$ and their expected range of variability are given in appendix A, along with that of $k$, an empirical parameter that relates $r_{\text {eff }}$ to the volume mean radius $r_{\text {vol }}$ and $\beta$, which describes the rate of increase of lwc with height. The very simple cloud model described by (3) predicts that $\tau, r_{\text {eff }}$ retrievals for clouds with low variability in the quantity $a_{1}^{1 / 5} N_{\text {sat }}^{-1 / 2}$ should exhibit the power-law relationship between $\tau$ and $r_{\text {eff }}$ observed in Fig. 2. Below we will focus on relative variability of $N_{\text {sat }}$ and lwp, and use satelliteretrieved values of $r_{\text {eff }}$ as estimates of cloud-top $r_{\text {eff }}$ in 

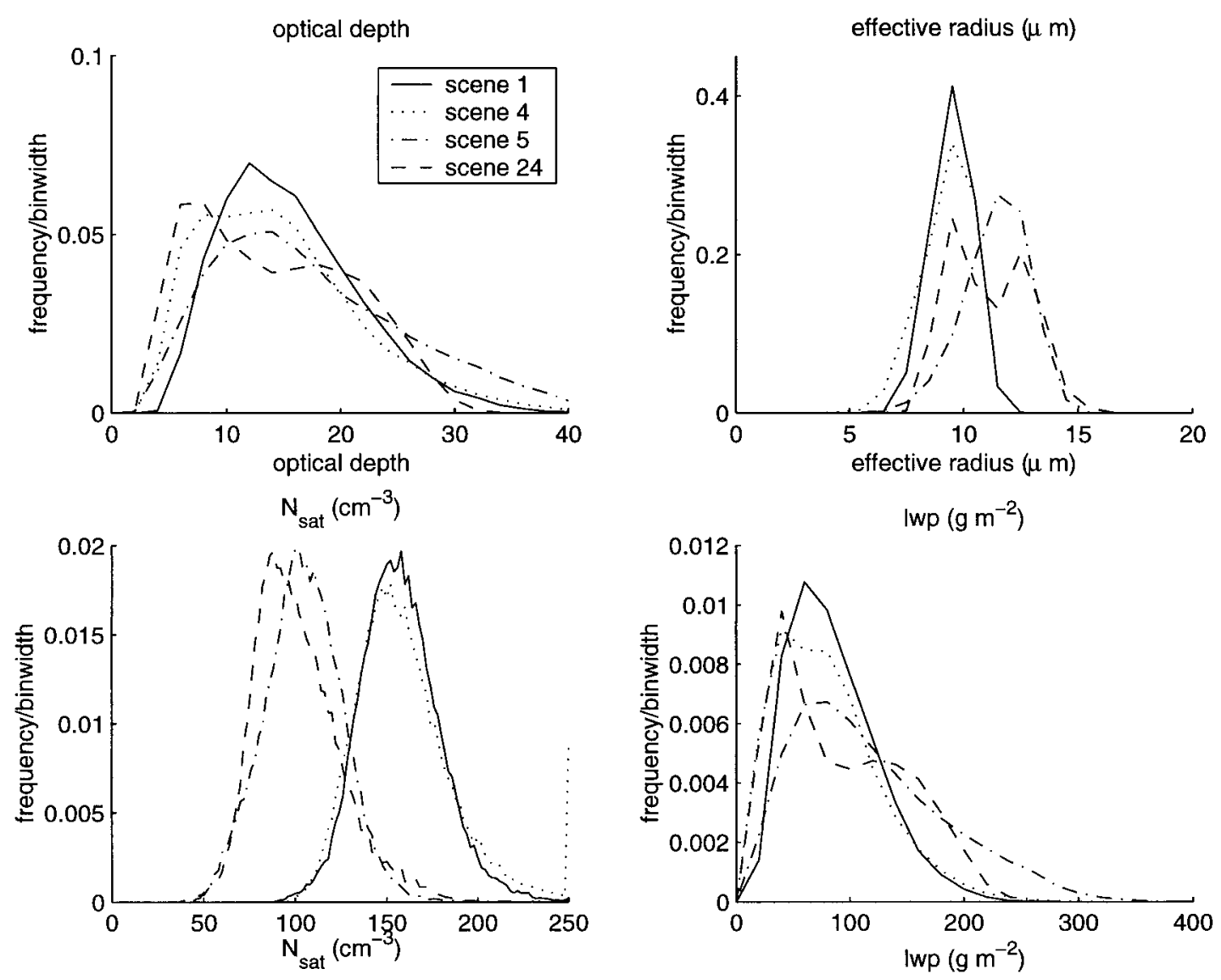

FIG. 3. Histograms of $\tau, r_{\text {eff }}, N_{\text {sat }}$, and lwp for the four scenes of Fig. 2.

(3). As mentioned in section $2 \mathrm{~b}$, this produces an underestimates of $r_{\text {eff }}$ in clouds for which $r_{\text {eff }}$ is increasing with height. Assuming uncorrelated errors in $\tau$ and $r_{\text {eff }}$, the impact on the derived quantities in (3) would be a $10 \%$ underestimate lwp and a $25 \%$ overestimate in $N_{\text {sat }}$ given a $10 \%$ underestimate in $r_{\text {eff }}$.

The assumptions in (3) that number concentration is roughly constant with height in the cloud and that liquid water content increases linearly with height are consistent with aircraft and balloon observations of both precipitating and nonprecipitating stratocumulus clouds in the north Atlantic, northeastern Pacific, and mid-Atlantic (e.g., Nicholls 1984; Caughey and Kitchen 1984; Austin et al. 1995; Khairoutdinov and Kogan 1999; Brenguier et al. 2000). A linear increase of liquid water content is also found in the mean lwc profiles of many numerical simulations of layer clouds, including models based on higher-order closure (e.g., Wang and Wang 1994) and two-dimensional large eddy simulations with bin-resolved microphysics (e.g., Khairoutdinov and Kogan 1999). There are also cases, however, in which both the assumptions of approximately constant droplet number concentration and a near-linear vertical profile of liquid water content are invalid. For example, decoupled cloud layers, and clouds in which droplets at cloud top are being removed by evaporation, violate both these assumptions and break the connection between $N_{\text {sat }}$ and cloud-top number concentration assumed in (3).

To help characterize these cloud layers we have included isolines of $N_{\text {sat }}=a_{1}^{1 / 2} \tau^{1 / 2} r_{\text {eff }}^{-5 / 2}$ and lwp $=a_{0} \tau r_{\text {eff }}$ in Fig. 2 and in the histograms for these scenes (Fig. 3 ), with values for $a_{0}$ and $a_{1}$ given in appendix A. Several studies have shown that the retrieval of lwp via (3c) from both AVHRR and Geostationary Operational Environmental Satellite (GOES) imager measurements of $\tau$ and $r_{\text {eff }}$ compares well with the surface microwave measurements of stratocumulus clouds of Han et al. (1995) and Greenwald et al. (1999). For example, Greenwald et al. (1999) report a root-mean-squared difference of $17 \mathrm{~g} \mathrm{~m}^{-2}$ between GOES imager and surface microwave data in a cloud layer with lwp values between 0 and $200 \mathrm{~g} \mathrm{~m}^{-2}$.

In situ and satellite comparisons for $N_{\text {sat }}$ are more difficult, because they require simultaneous knowledge of the cloud microphysics $(N, k)$ and the bulk thermodynamics $\left(\beta, a_{1}\right)$. Han et al. (1998b) compare satellite retrievals of a related quantity (the column number concentration $N_{c}$ or product of the droplet number $N$ and layer thickness $H$ ), for four aircraft flights in marine stratocumulus, and show 2 factor of 2 agreement be- 
tween in situ and retrieved $N_{c}$ values. In light of the uncertainties itemized in section $2 \mathrm{~b}$ and appendix $\mathrm{A}$ and the assumptions underlying the relation between $\tau, r_{\text {eff }}$ and the droplet concentration $N$ in (3), we will focus here on contrasts between $N_{\text {sat }}$ and lwp variability, recognizing that large variations in $N_{\text {sat }}$ could originate from fluctuations in cloud microphysics or departures from the assumptions underlying (3c), while small $N_{\text {sat }}$ variance could arise from compensating fluctuations in some or all of $N, k$, and $\beta$.

In Fig. 3 we compare the $\tau, r_{\text {eff }}, N_{\text {sat }}$, and lwp distributions for the scenes shown in Fig. 2. The mean liquid water paths for scenes $1,4,5$, and 24 range from 80 to $116 \mathrm{~g} \mathrm{~m}^{-2}$, which are typical of thinner clouds observed by ground-based and satellite microwave radiometer measurements for this region (Han et al. 1995; Zuidema and Hartmann 1995). The $N_{\text {sat }}$ distributions for all four scenes are nearly normal, with values of skewness defined as

$$
B=\frac{\overline{\left(N_{\mathrm{sat}}-\overline{N_{\mathrm{sat}}}\right)^{3}}}{\sigma^{3}},
$$

ranging from $10^{-3}$ to $10^{-2}$, or 5-10 times smaller than that for the lwp distributions. The lwp and optical depth distributions for scenes 1, 4, and 5 are positively skewed, and are well fit with either gamma or lognormal distributions. In contrast, scene 24 is characterized by a unimodal $N_{\text {sat }}$ distribution and bimodal distributions of $\tau, r_{\text {eff }}$, and lwp. Images of these retrieved values (not shown) show that the scene contains two distinct regions with lwp maxima of 33 and $151 \mathrm{~g} \mathrm{~m}^{-2}$ but similar $N_{\text {sat }}$ distributions with modes of 78 and $83 \mathrm{~cm}^{-3}$, respectively.

While the power-law relationship between $\tau$ and $r_{\text {eff }}$ shown in Fig. 2 occurs frequently, the majority of the 400 scenes for which retrievals have been performed have more complex $\tau, r_{\text {eff }}$ variability. Figures $4-7$ show representative examples of these more complex clouds. Figures $4 \mathrm{a}$ and $4 \mathrm{~b}$ shows two scenes ( 9 and 10) that are similar to the bimodal scene 24 of Fig. 2 d, with spatially distinct regions with differing $r_{\text {eff }}$ distributions. To highlight this spatial separation we have shown images of the two scenes in Figs. 4c and 4d, with the pixel colors assigned according to whether the $N_{\text {sat }}$ values are greater or less than 85 and $30 \mathrm{~cm}^{-3}$, respectively. These two scenes differ from scene 24 in that the $N_{\text {sat }}$ statistics are distinct in each subregion, as indicated by the bimodal $N_{\text {sat }}$ distributions in Fig. 5c. The contrasting joint $\tau, r_{\text {eff }}$ distributions are consistent with other AVHRR retrievals showing sharp contrasts between cloud properties across 100-km regions (e.g., Nakajima and Nakajima 1995). Scenes 7 and 8 (not shown) also exhibit this kind of spatially distinct variation in $N_{\text {sat }}$.

Figures 6 and 7 show a third type of $\tau, N_{\text {sat }}$ variability found in thicker clouds, defined as layers with mode optical depths larger than 20. In these four layers the mean liquid water path exceeds $100 \mathrm{~g} \mathrm{~m}^{-2}$, while the mean $r_{\text {eff }}$ for each scene is between 8.5 and $12.5 \mu \mathrm{m}$. Scene 14, from 16 July 1987, is also shown as a scatterplot in Nakajima and Nakajima (1995; their Fig. 17, panel B-3). This scene has pixels with $r_{\text {eff }}>15 \mu \mathrm{m}$, for $\tau<20$, but smaller $r_{\text {eff }}$ values at larger $\tau$. As Nakajima and Nakajima (1995) remark, the absence of pixels with both large lwp and large $r_{\text {eff }}$ may be due to the removal of water by precipitation in thick cloud with low number concentrations, where droplets are large enough to permit collision-coalescence. In contrast, however, scene 10 (Fig. 4) shows retrieved pixels with effective radii larger than $20 \mu \mathrm{m}$ at optical depths greater than 20 and lwp $>270 \mathrm{~g} \mathrm{~m}^{-2}$.

The means of the distributions of $\tau, r_{\text {eff }}, 1 w p$, and $N_{\text {sat }}$ for all 25 scenes are summarized in Fig. 8. We distinguish in the figure between the 17 scenes for which the linear regression of $r_{\text {eff }}, \tau$, as described for Fig. 2, yields $b=0.2$ within the uncertainty of the fit, and other clouds (circled scene numbers in Fig. 8). The criterion that $b$ $=0.2$ within the regression uncertainty is met by 17 of the 25 scenes in Fig. 1. Mean optical depths for these scenes range from 7.8 to 20 , while mean effective radii vary from 6.6 to $13 \mu \mathrm{m}$, with larger mean optical depths generally corresponding with larger mean $r_{\text {eff }}$. In contrast, mean values of $\tau$ and $r_{\text {eff }}$ are uncorrelated for the eight (circled) scenes which for which $b \neq 0.2$.

Figure 9 shows the means of the two derived quantities $N_{\text {sat }}$ and lwp together with the standard deviation for each quantity. As expected, for all scenes in which regression yields $r_{\text {eff }} \propto \tau^{1 / 5}$, the $N_{\text {sat }}$ standard deviation $\left(\sigma_{N}\right.$ sat) normalized by the mean is more than three times the size of the normalized standard deviation of lwp. The trend for these scenes is for higher values of $N_{\text {sat }}$ to occur in thinner cloud. There is little systematic geographical variation in $N_{\text {sat }}$ value with distance offshore; the location of scenes with $N_{\text {sat }}>200 \mathrm{~cm}^{-3}$ ranges from 100 to more than $1000 \mathrm{~km}$ offshore. There is also no obvious retrieval bias with view angle or optical depth: both large and small normalized $N_{\text {sat }}$ deviations occur across the entire range of $\tau$ and lwp, and across a mean view angle range of $5^{\circ}-48^{\circ}$ (see Table B1).

\section{b. In situ measurements}

In this section we present coincident aircraft and satellite measurements of stratocumulus cloud layers observed during six flights flown to the west of Cape Grim, Tasmania, as part of SOCEX II. Boundary layer clouds during SOCEX II were typically cumulus penetrating into stratocumulus, with the solid cloud layer being approximately 400-600 m thick, and overall cloud layer being approximately $1 \mathrm{~km}$ thick. The six analyzed SOCEX II flights are listed in Table B2, together with the time of the matching satellite overpass. Thermodynamic profiles on most flights show discontinuities indicating decoupling between cloud and subcloud layers. All flights with the exception of flight 7 reported drizzle, with the largest rainfall rates reaching 50-60 $\mathrm{mm} \mathrm{day}^{-1}$ 

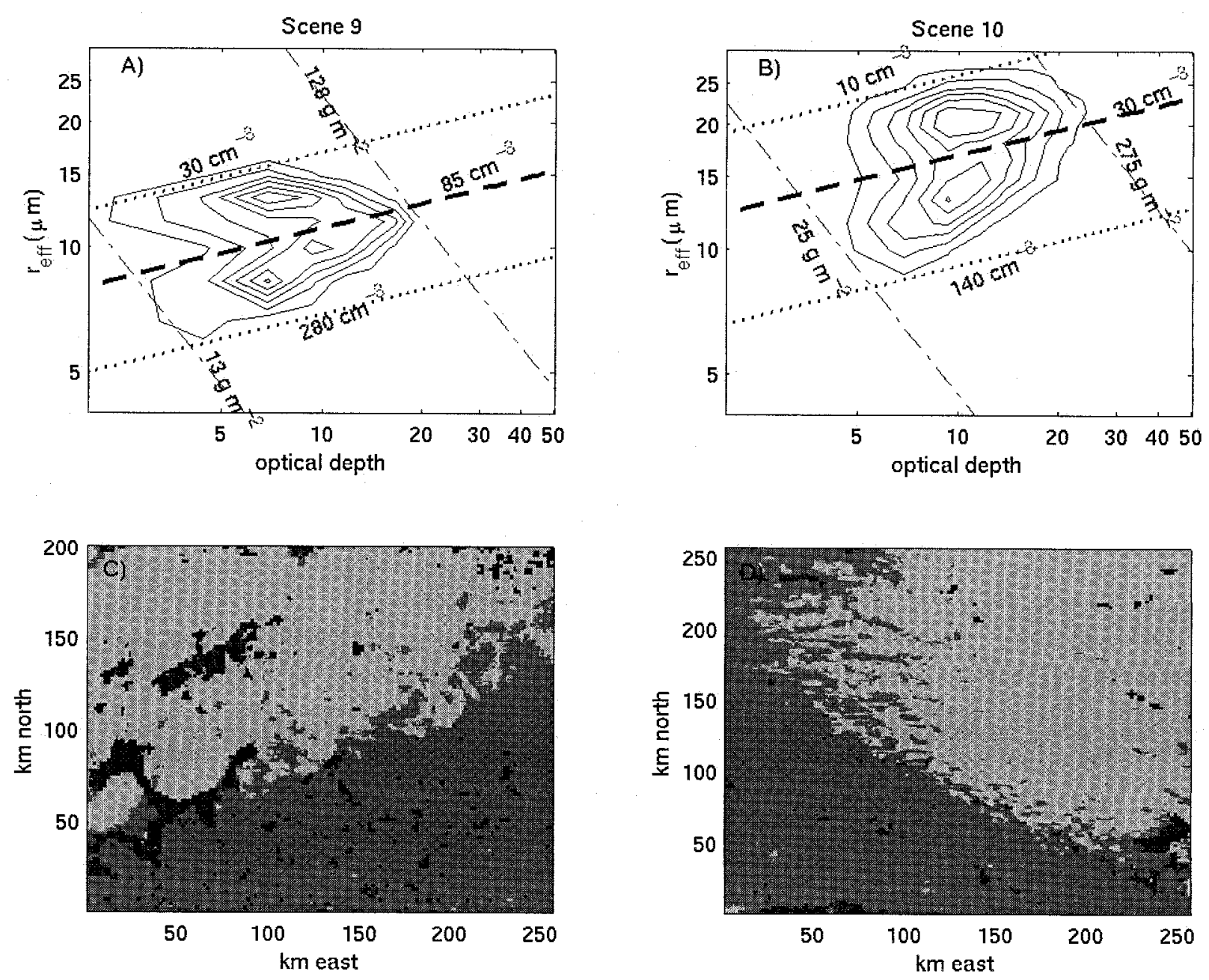

FIG. 4. (a) and (b) As in Fig. 2, but for two scenes with strongly bimodal distributions of $N_{\text {sat }}$. The heavy dashed $N_{\text {sat }}$ isoline in each contour plot separates large $r_{\text {eff }}$ pixels from small $r_{\text {eff }}$. These pixels are then colored black (small $r_{\text {eff }}$ ) and gray (large $r_{\text {eff }}$ ) in the maps below each contour plot [(c) and (d)]. Clouds with bimodal $N_{\text {sat }}$ distributions are denoted by a $\bigcirc$ in Fig. 1.

and $20-30 \mathrm{~mm}$ day $^{-1}$ on flights 8 and 11 , respectively. Effective radii reported here are calculated using dropsize distributions measured using the forward scattering spectrometer probe (FSSP) and 2DC probes on board the F27 aircraft as described in Boers et al. (1996). Sampling and sizing errors in the FSSP introduce uncertainties of at least $10 \%$ in droplet radius and $10 \%$ in number concentration (Baumgardner and Spowart 1990).

Figure 10 shows a vertical profile of the flight path of a typical SOCEX II flight mission (flight 10); SOCEX flight missions consisted of several horizontal stacks flown at different levels within a cloud layer. Flights lasted 3-4 h, with the horizontal in-cloud legs covering 30-35 km over $7 \mathrm{~min}$. The aircraft drifted with the wind, so that during a typical flight of $150 \mathrm{~min}$ a vertical plane $30-35 \mathrm{~km}$ long was repeatedly sampled. As Fig. 10 illustrates, there were typically six to eight encounters within 100-200 m of cloud top, ranging from samples of several seconds on ascent/descent to 7-min horizontal samples on level legs.

The flight pattern shown in Fig. 10 allows us to obtain a picture of the vertical structure of the cloud layer over the 150-min period of a stack set. Based on this, we are able to make a rough estimate of the cloud adiabaticity $\beta$ for these clouds by taking the composite vertical liquid water profile from the stacks and comparing it to an adiabatic profile taken from the mean cloud base. Figure 11 shows these estimates of $\beta$ from the six SOCEX II flights plotted against total droplet number concentration $N$ (with its standard deviation), along with single sounding estimates for the FIRE region of section 4a taken from Austin et al. (1995). The error bars for the SOCEX II flights are calculated from the uncertainty in $d \mathrm{lwc} / d z$ given by the least squares fit to the stack profile data, neglecting the FSSP sizing errors and the uncertainty associated with the variable cloud base characteristic of the SOCEX clouds. The figure shows that the 

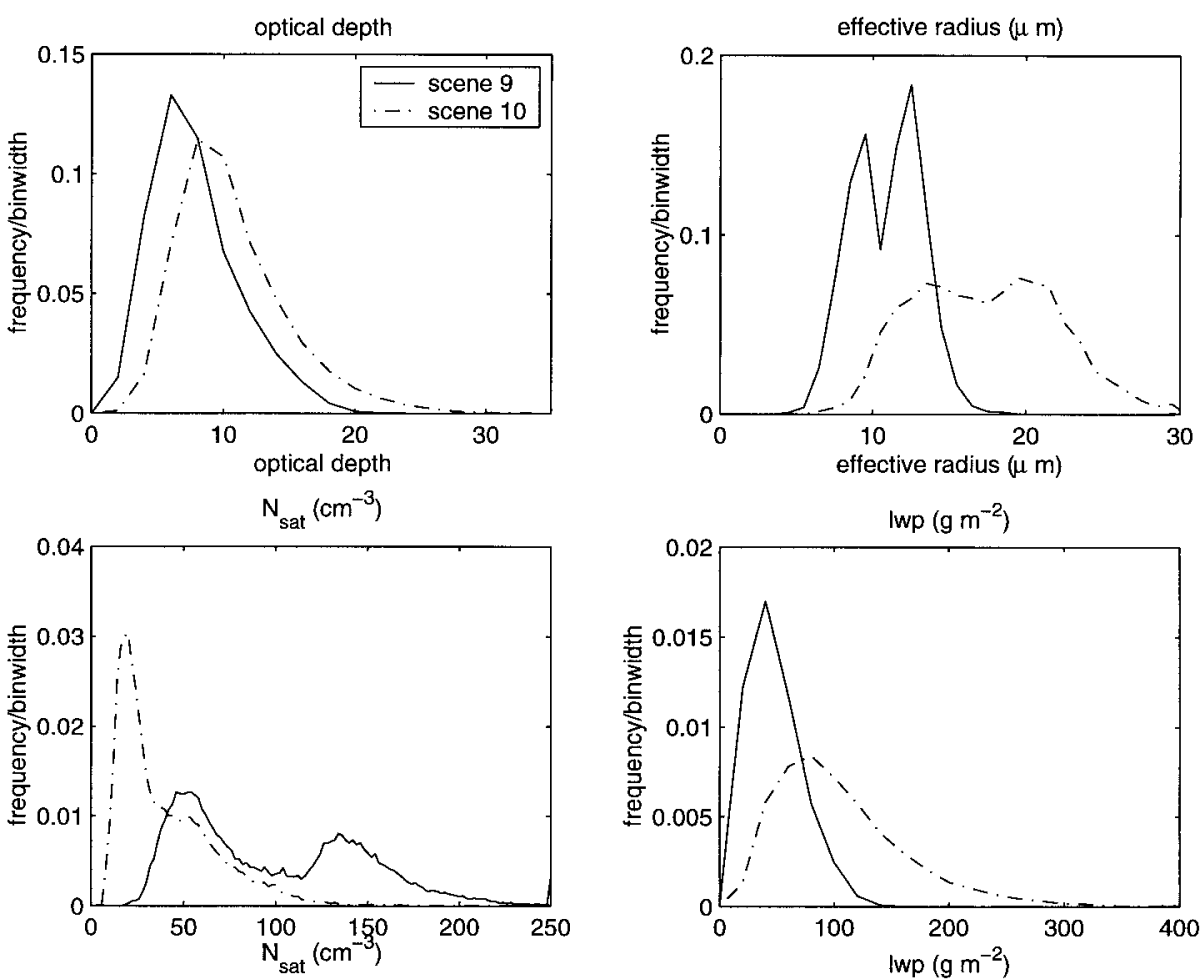

FIG. 5. Histograms of $\tau, r_{\text {eff }}, N_{\text {sat }}$, and lwp for the two scenes of Fig. 4.
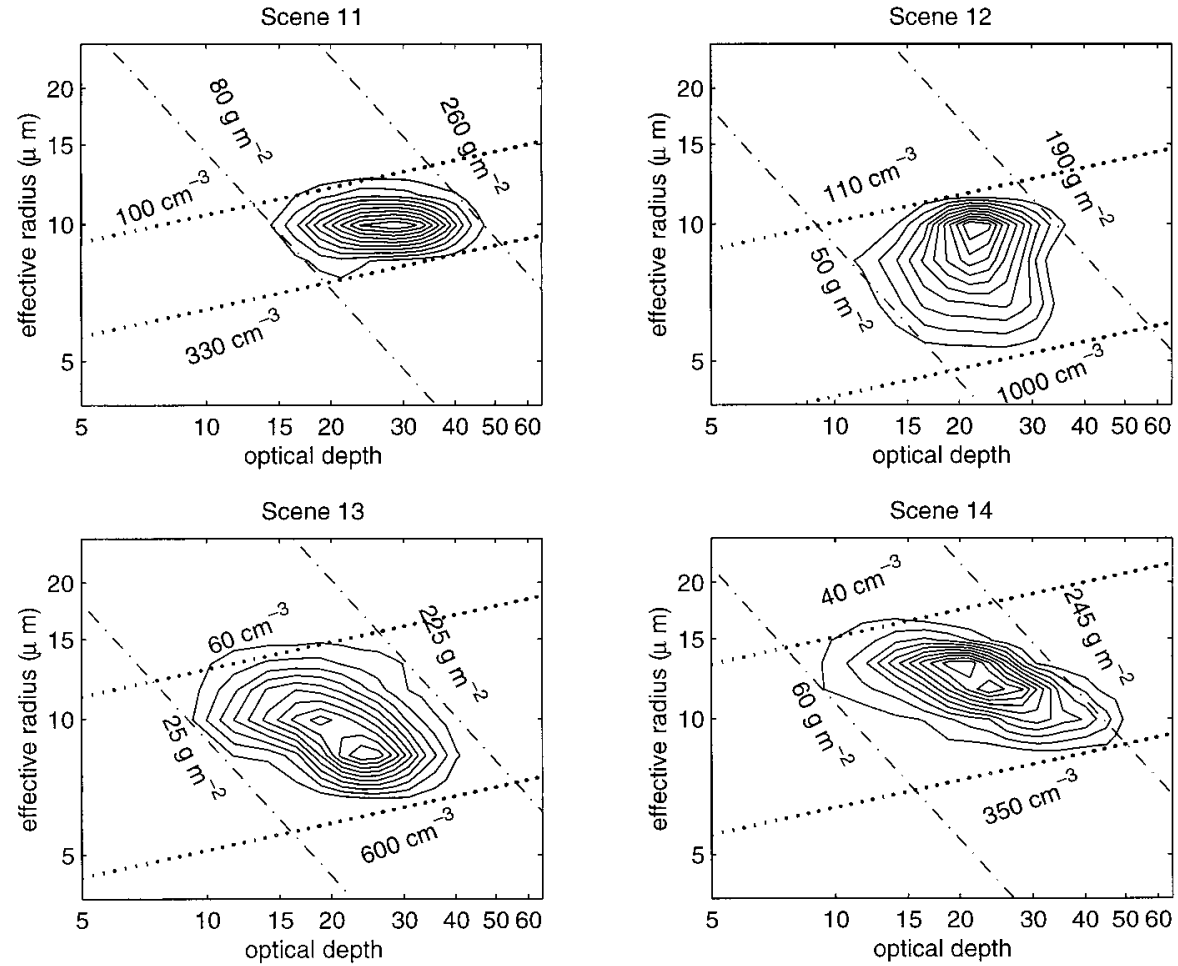

FIG. 6. As in Fig. 2, but for four scenes with thicker cloud layers. Thick cloud scenes are denoted with a $\triangle$ in Fig. 1. 

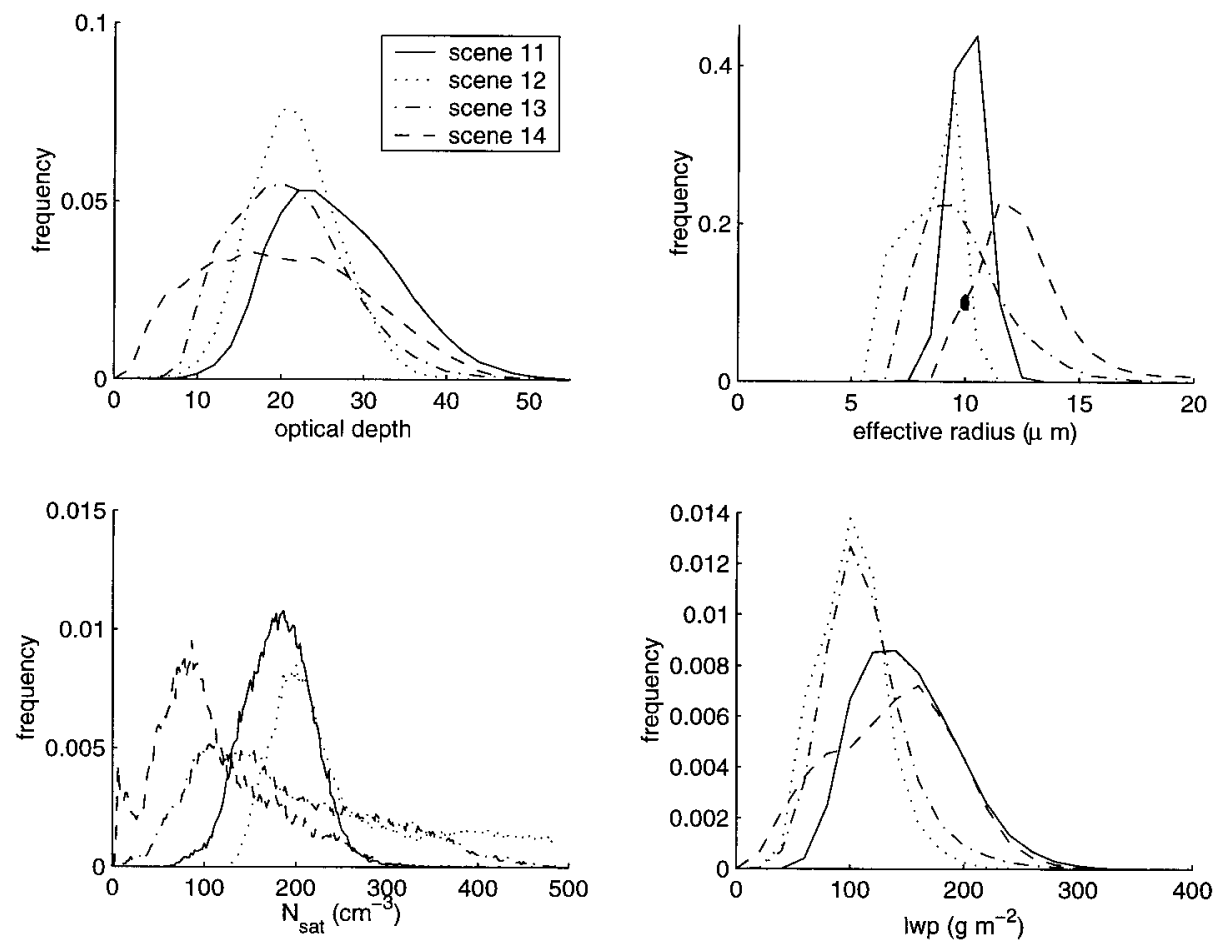

FIG. 7. Histograms of $\tau, r_{\text {eff }}, N_{\text {sat }}$, and lwp for the four scenes of Fig. 6.

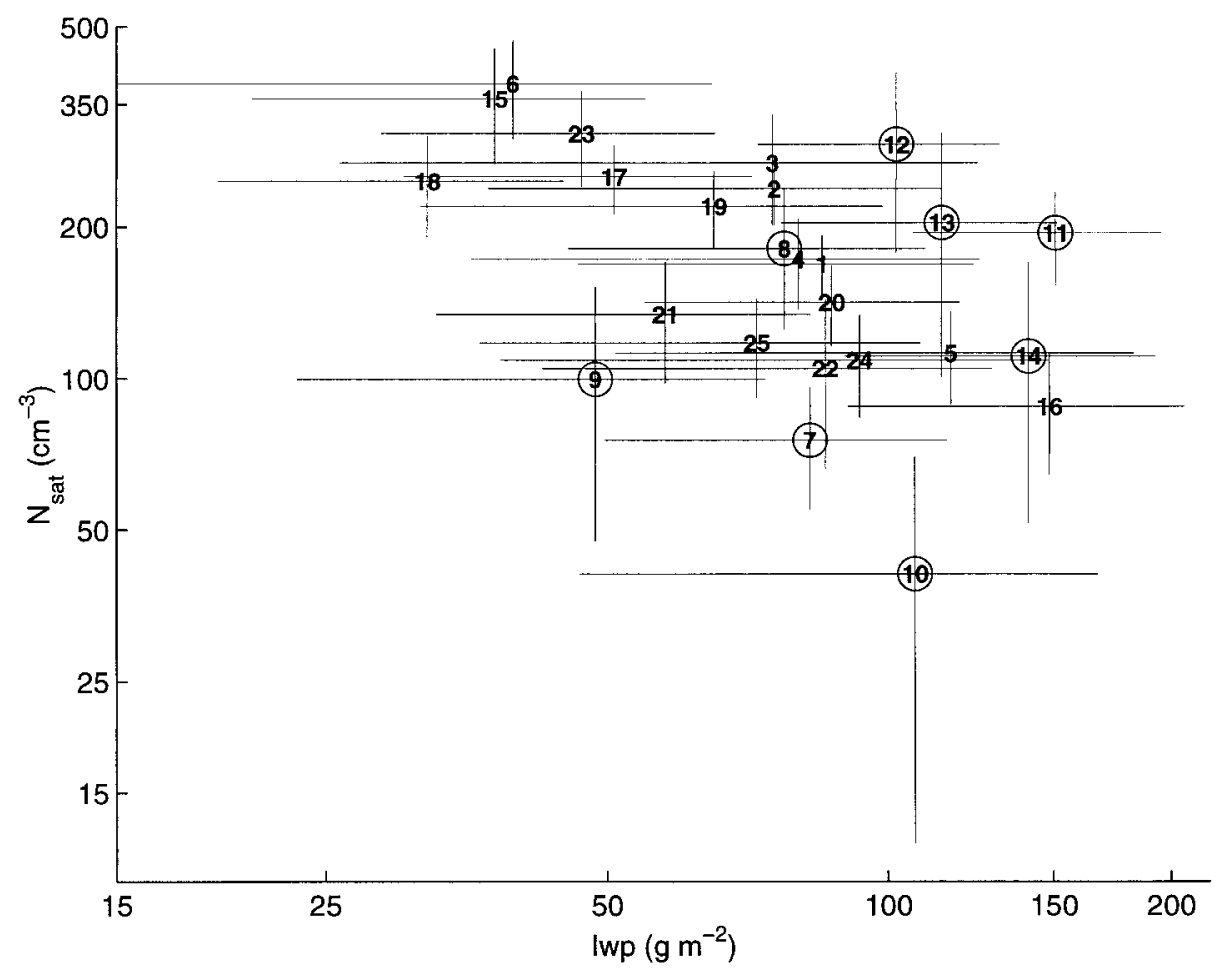

FIG. 8. Scatterplots of the mean values of $r_{\text {eff }}, \tau, N_{\text {sat }}$, and lwp for all 25 northeastern Pacific scenes of Fig. 1. The eight scenes with circled numbers correspond to scenes with bimodal $N_{\text {sat }}$ distributions or mean $\tau>20$. 


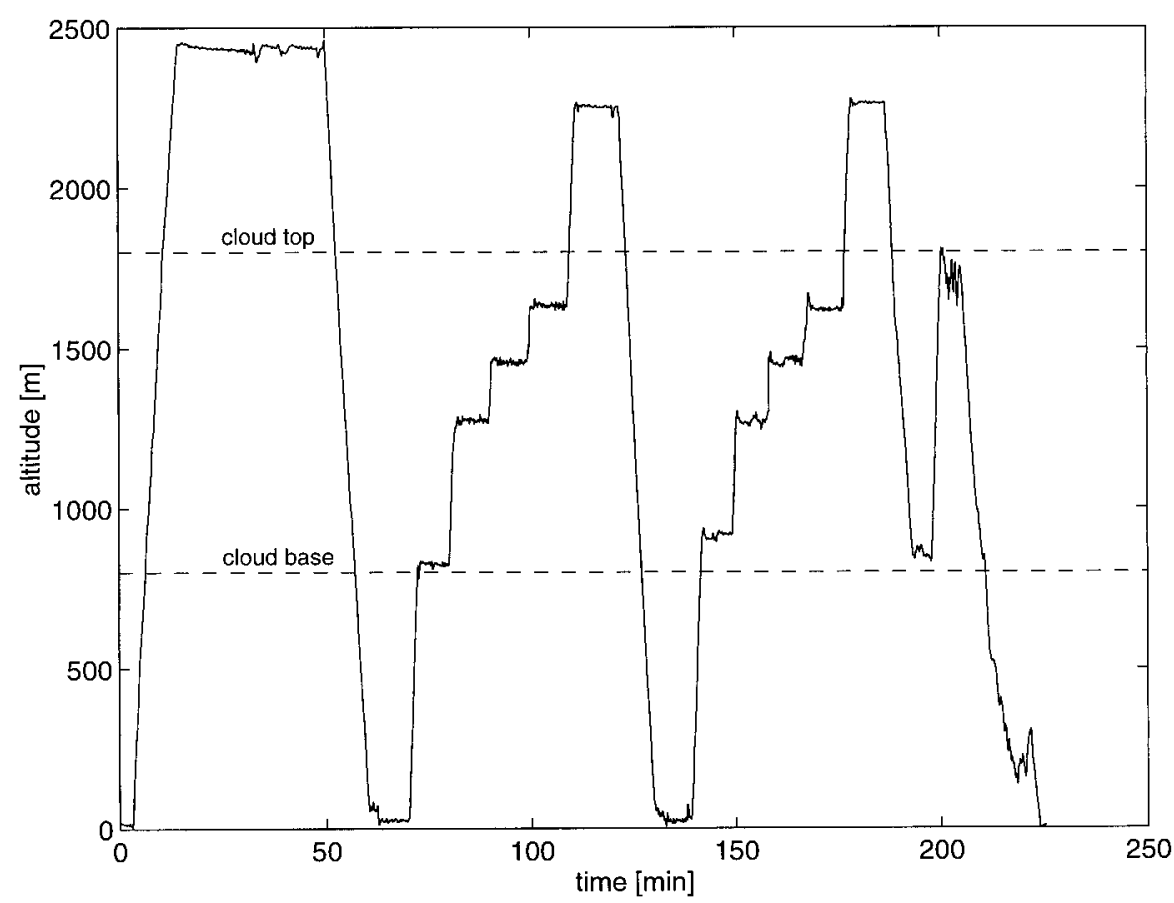

FIG. 9. As in Fig. 8, but for lwp vs $N_{\text {sat }}$. Solid lines indicate \pm one standard deviation about the mean value.
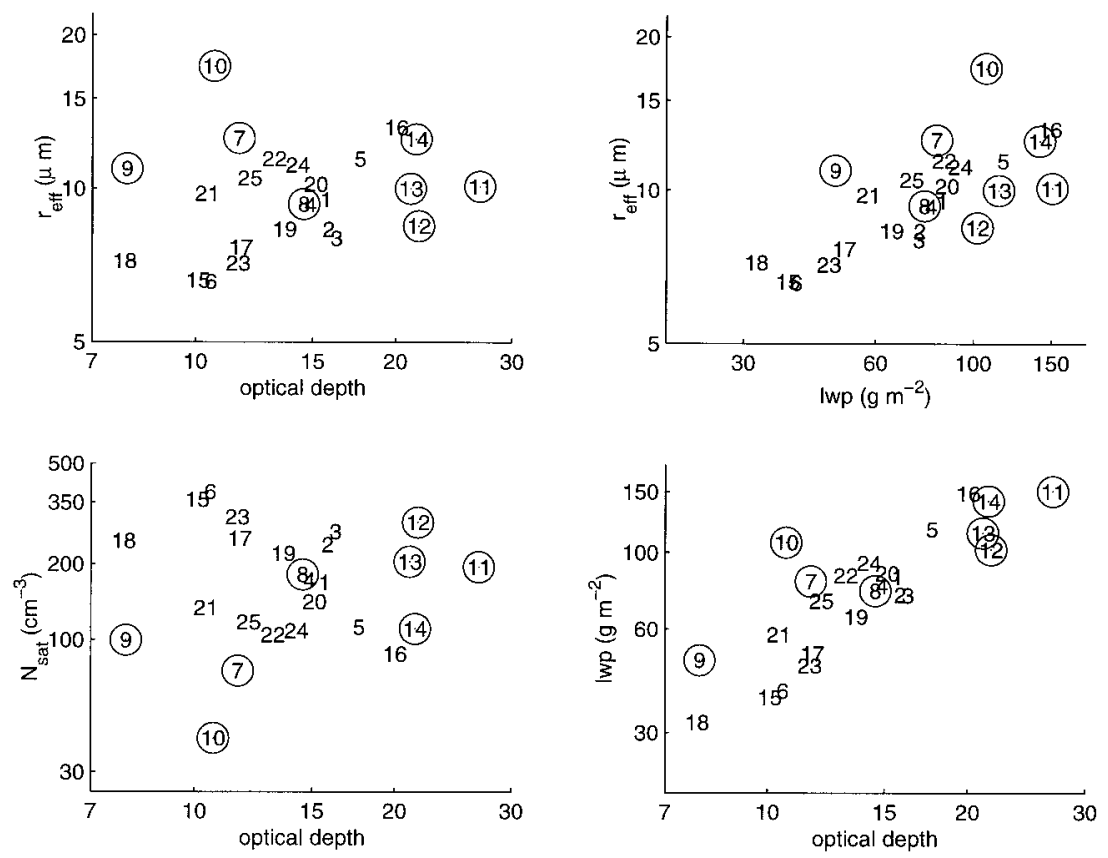

FIG. 10. Aircraft vertical cloud sampling pattern (horizontal stacks) in SOCEX II flight 10. Time is in min from the start of the flight. Flight average cloud top and cloud base are indicated by the dashed lines. 


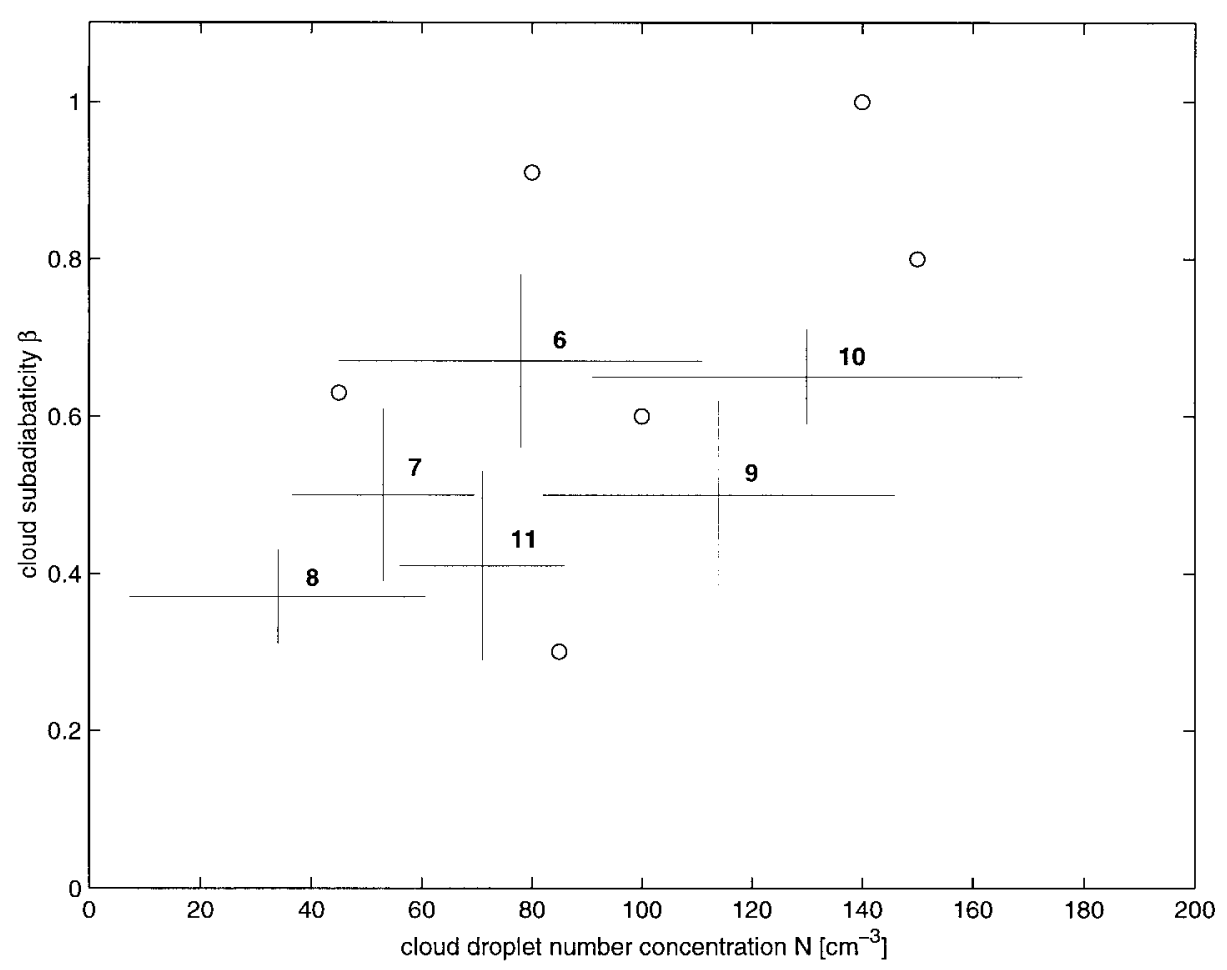

FIG. 11. Scatterplot of cloud adiabaticity $\beta=(d \mathrm{lwc} / d z) /\left(d \mathrm{lwc}_{\text {adiab }} / d z\right)$ vs cloud droplet number concentration for the six SOCEX II flights (numbers) and for FIRE soundings $(O)$ [using FIRE data from Austin et al. (1995)]. Vertical error bars from the least squares fit to the stack profile of lwc, horizontal error bars are \pm one standard deviation.

SOCEX II $\beta$ values tend to be slightly lower than those taken from FIRE, which is consistent with the observations of both penetrative cumulus convection and decoupling in the thermodynamic profiles, and drizzle resulting in the removal of cloud liquid water for these clouds. These values can be compared with measurements of $0.4<\beta<0.7$ for wintertime stratocumulus in the SOCEX II region (Boers et al. 1996).

Figure 12 shows the aircraft estimates of $r_{\text {eff }}$ and $\tau$ together with $\log -\log$ contour plots of the coincident AVHRR retrievals. In each panel, the values of $r_{\text {eff }}$ at or near cloud top have been denoted with circles, while aircraft measurements of $r_{\text {eff }}$ below cloud top are shown as asterisks. We have assigned an approximate optical depth to each aircraft $r_{\text {eff }}$ value by integrating the mean sounding produced by all the level legs in a stack. In clouds with large horizontal inhomogeneities such as these, this will be a poor estimate of $\tau$ in any particular pixel. Given the irregular cloud base, penetrating cumulus turrets, and convective lines observed in these layers, we expect that the actual column-integrated optical depths might be significantly higher than those indicated by the time-averaged mean values presented here.

Given this limitation in the aircraft $\tau$ estimates, Fig. 12 does show good agreement between satellite and in situ estimates of cloud-top $r_{\text {eff }}$. For flights 6 and 11 the satellite retrieves large values of $\tau$ with little variability in $r_{\text {eff }}$. For flight 6 the mean values for the in situ and satellite-estimated $r_{\text {eff }}$ are within $0.7 \mu \mathrm{m}$ (13.9 $\mu \mathrm{m}$ for AVHRR vs 13.2 for the aircraft). Similar agreement is found in flight $11(14.0 \mathrm{vs} 13.5 \mu \mathrm{m})$. In flights 7 and 8 the cloud-top values of $r_{\text {eff }}$ varied between 5-10 (flight 7) and 9-12 $\mu \mathrm{m}$ (flight 8), a range that is encompassed in the satellite retrievals for these layers, although the aircraft sampled significantly thinner cloud than the satellite retrievals for flight 7 . For flight 9 the aircraftmeasured values of $r_{\text {eff }}$ are smaller than $10 \mu \mathrm{m}$, in contrast to $12-\mu \mathrm{m}$ radii found by the satellite in the thinest pixels subject to retrieval. In this broken cloud, as in flight 7 , it is likely that some flight-leg pixels have been rejected because of failure to meet the spatial coherence criteria. Subvisible cirrus contamination is also a possibility for this cloud; there are patches of cirrus away from the flight line in this image, although no high clouds are discernible in the Coakley-Bretherton diagram for flight 9.

Overlying each of the contour plots in Fig. 12 is an $N_{\text {sat }}$ isoline equal to the mean $N_{\text {sat }}$ for the scene. For flights 9 and 10 this isoline is also within $1 \%-2 \%$ of the value of the log-log regression, which gives an average slope of $b=0.2 \pm 0.01$ in each case. Although we expect these complicated, precipitating cloud layers to both have larger uncertainties in the retrieved values of $\tau$ and $r_{\text {eff }}$ and larger variability in $\beta$ and $k$, we can qualitatively compare the distributions of $N_{\text {sat }}=$ 
Flight 6
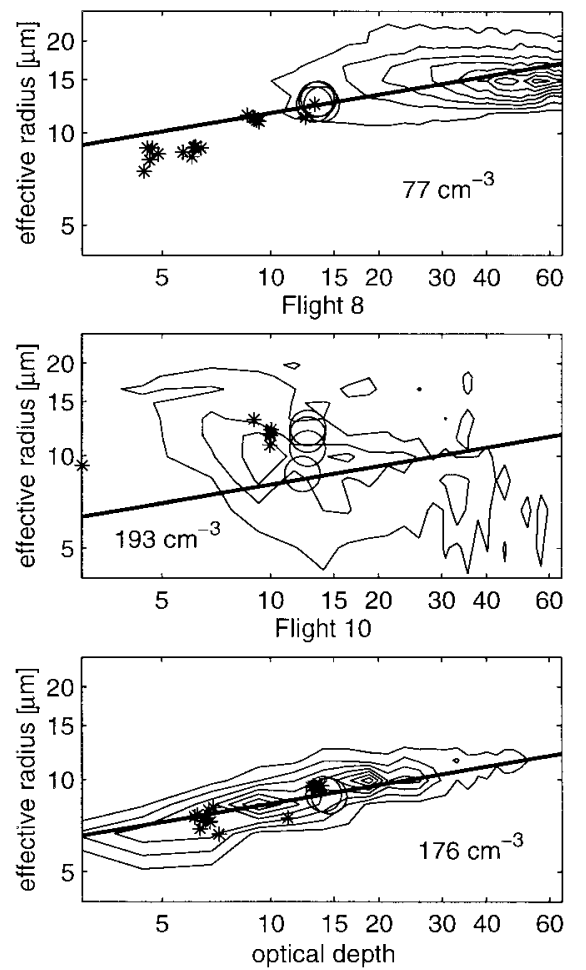

Flight 7
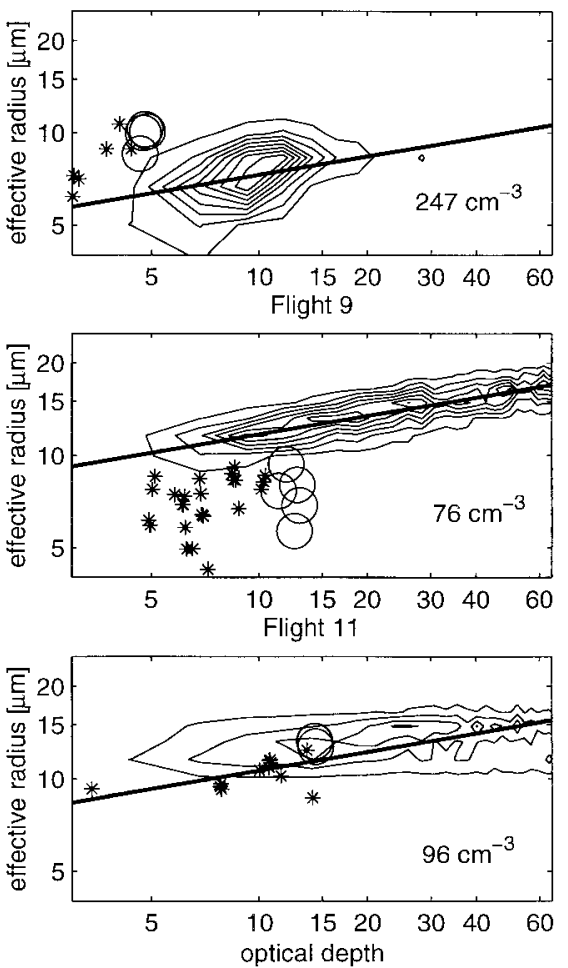

FIG. 12. $\log -\log$ contour plots of the retrieved $\tau, r_{\text {eff }}$ frequency density $\eta$ (as in Fig. 2) for the six SOCEX II flights. Open circles denote aircraft-measured $r_{\text {eff }}$ at or near cloud top, while asterisks denote $r_{\text {eff }}$ measurements below cloud top. $N_{\text {sat }}$ isolines for the mean $N_{\text {sat }}$ for each scene are also shown with the mean $N_{\text {sat }}$ values indicated in each panel.

$a_{1}^{1 / 2} \tau^{1 / 2} r_{\text {eff }}^{-5 / 2}$ shown in Fig. 12 with the in situ measurements of $N$ and $\beta$ given in Fig. 11, assuming that $N=$ $N_{\text {sat }} \sqrt{\beta} / k$. Taking $k=0.8$, using the mean $\beta$ for each flight gives satellite-retrieved values of $N$ for flights 6 , 10 , and 11 of $N=77,176$, and $76 \mathrm{~cm}^{-3}$, respectively. These are within the range of $N \pm \sigma_{N}$ given in Fig. 11, although the maximum in situ number concentrations observed in flights 10 and $11\left(250\right.$ and $\left.110 \mathrm{~cm}^{-3}\right)$ are lower than the maximum inferred from $N_{\text {sat }}$ (350 and $181 \mathrm{~cm}^{-3}$, respectively). As noted in section $4 \mathrm{a}$ we expect satellite-retrieved $r_{\text {eff }}$ to underestimate the cloudtop $r_{\text {eff }}$, which would produce overestimates of $N_{\text {sat }}$. There is little agreement between the in situ $N$ and the $N_{\text {sat }}$ estimates for the other flights, again possibly due to a sample mismatch between the Lagrangian aircraft trajectories and the location of successfully retrieved pixels.

\section{Discussion}

Several authors [e.g., Han et al. (1994, p. 493); Nakajima and Nakajima (1995, p. 4057); Han et al. (1998a)] have noted the tendency for satellite-retrieved $r_{\text {eff }}$ to increase with increasing $\tau$ in thinner clouds, and decrease with increasing $\tau$ in optically thicker clouds. In light of Figs. 2, 4, and 6, we can be more quantitative about the variability of $\tau$ and $r_{\text {eff }}$ in thinner clouds $(\tau<$ 20): we find that a power law of the form $r_{\text {eff }} \propto \tau^{1 / 5}$ captures much of the variability between $\tau$ and $r_{\text {eff }}$ in 19 of the 31 layers we presented. Twenty-five of these scenes are drawn from a larger sample of 404 images taken from 67 satellite swaths during several summers in the northeastern Pacific. Of these 404 scenes, 40\% also show a power-law relationship with an exponent equal to $1 / 5$ within the uncertainty of the $\log \tau-\log r_{\text {eff }}$ regression. Other scenes in this ensemble with similar values of optical depth, cloud fraction, satellite view, and solar zenith angles show larger $r_{\text {eff }}$ variability and little correlation between $\tau$ and $r_{\text {eff }}$.

Recently, Brenguier et al. (2000) have inferred distributions of cloud droplet number concentration from remotely sensed $\tau, r_{\text {eff }}$ retrievals. Using an aircraftmounted two-channel radiometer flown in the mid-Atlantic during the Second Aerosol Characterization Experiment, they retrieved $\tau$ and $r_{\text {eff }}$, while simultaneously measuring cloud thickness and droplet size spectra from a second in situ aircraft. Figure 8 of their paper maps the two-channel reflectances to droplet number concentration assuming an adiabatic liquid water content profile and constant number concentration in the column beneath the radiometer; there is good agreement between the number concentration inferred from this sim- 
ple model and the in situ samples, and a strong correlation of the two-channel radiance along isolines of constant number concentration.

It is possible to make a similar interpretation of the satellite retrievals presented here, provided that the assumptions of a vertically uniform mean droplet concentration and linearly increasing mean liquid water content hold on the 1-km horizontal scale of the satellite pixels. In that case isolines of $N_{\text {sat }} \propto \tau^{1 / 2} r_{\text {eff }}^{-5 / 2}$ map to constant values of $k N / \sqrt{\beta}$. We expect both precipitation and entrainment to produce a negative correlation between $N$ and $\beta$ (cf. Fig. 11), while Martin et al. (1994) show evidence for negative correlation between $N$ and $k$, so that if the simple model holds, $N_{\text {sat }}$ variability likely places only a lower bound on the variability of $N$ in these thinner layer clouds.

In the survey of northeastern Pacific scenes from which the 25 retrievals are taken we find that clouds with mean optical depths greater than 20 typically exhibit lower $\left(\tau, r_{\text {eff }}\right)$ correlations. As SOCEX flights 9 and 10 show, however, a power law of the form $r_{\text {eff }} \propto$ $\tau^{1 / 5}$ can at least occasionally describe variability in thicker clouds with significant precipitation. Simultaneous measurements of lwp, cloud-top $r_{\text {eff }}$, and optical depth, combined with a quantitative description of $\tau, r_{\text {eff }}$ retrieval uncertainties using three-dimensional radiative transfer models, would be very useful in determining the underlying physical constraints on the variability in lwp and cloud droplet number concentration for these layer clouds.

Acknowledgments. We are grateful to Takashi Nakajima and Teruyuki Nakajima for providing the source code for the retrieval algorithm used in this paper, along with numerous helpful discussions, and to Jorgen Jensen, whose comments improved this paper. The paper was improved by comments from Teruyuki Nakajima and two anonymous referees. Our research was supported by grants from the Canadian Atmospheric Environment Service, the National Science and Engineering Research Council of Canada, and the Commonwealth Scientific and Industrial Research Organisation of Australia (CSIRO). SOCEX was partly funded by the CSIRO Office for Space Science and Applications (COSSA), the Cooperative Research Centre for Southern Hemisphere Meteorology, and CSIRO's Multi-Divisional Climate Change Research Program. Thanks for SOCEX work are due to Jorgen Jensen, Reinout Boers, Sunhee Lee, Dan Gogoasa, Bernard Petraitis, and other staff at CSIRO Atmospheric Research.

\section{APPENDIX A}

\section{Simple Relations among $\tau, r_{\text {eff }}, N_{\text {sat }}$, and lwp}

Several authors have derived the relationship between the retrieved variables $\tau$ and $r_{\text {eff }}$, the number concentration $N$, and the liquid water path lwp for a simple adiabatic cloud layer (e.g., Pontikis 1993; Boers and Mitchell 1994). Below we adopt the notation of Brenguier et al. (2000), using an additional term $(\beta)$ to represent the departure of the liquid water content profile from adiabatic.

Denoting the number concentration at height $z$ with radii between $r, r+d r$ as $n(r, z) d r$, the definitions for the total droplet concentration $N$, effective radius $r_{\text {eff }}$, the volume mean radius $r_{\text {vol }}$, the liquid water content $w$, liquid water path lwp, and the optical depth $\tau$ are given by

$$
\begin{aligned}
r_{\mathrm{eff}}(z)= & \frac{\int_{0}^{\infty} n(r, z) r^{3} d r}{\int_{0}^{\infty} n(r, z) r^{2} d r}, \\
N(z)= & \int_{0}^{\infty} n(r, z) d r, \\
w(z)= & \frac{4}{3} \rho_{w} \int_{0}^{\infty} n(r, z) \pi r^{3} d r, \\
r_{\mathrm{vol}}(z)= & \left(\frac{3 w(z)}{4 \pi N(z) \rho_{w}}\right)^{1 / 3}, \\
\operatorname{lwp} & =\int_{0}^{H} w(z) d z, \\
\tau & =Q_{\mathrm{ext}} \int_{0}^{H}\left[\int_{0}^{\infty} n(r, z) \pi r^{2} d r\right] d z,
\end{aligned}
$$

where $\rho_{w}$ is the density of water, $z$ is the height above cloud base, $H$ is the cloud thickness, and $Q_{\text {ext }}$ is the mean scattering efficiency.

We will assume that the mean number concentration is roughly constant with height in the $1 \mathrm{~km}^{2}$ AVHRR pixel $(N(z)=N)$, and that the mean liquid water content increases linearly with height at some fraction $\beta$ of its adiabatic value

$$
w(z)=\beta C_{w} z
$$

where $C_{w}$, termed the moist adiabatic condensate coefficient by Brenguier et al. (2000), is a weak function of temperature and pressure, varying between 1.8 and $2.25 \times 10^{-3} \mathrm{~g} \mathrm{~m}^{-3} \mathrm{~m}^{-1}$ in the temperature range $280-$ $290 \mathrm{~K}$ at $980 \mathrm{hPa}$. Substituting (A2) into (A1f), integrating, and using the empirical relationship between $r_{\text {eff }}^{3}$ and $r_{\text {vol }}^{3}$ found by Martin et al. (1994) gives a slightly modified version of Eq. (12) of Brenguier et al. (2000):

$$
\tau=\frac{3}{5} \pi Q_{\mathrm{ext}} A^{2 / 3} \beta^{2 / 3}(k N)^{1 / 3} H^{5 / 3},
$$

where $A=C_{w} /(4 / 3) \pi \rho_{w}$, and the coefficient $k$ was found by Martin et al. (1994) to vary from 0.67 to $0.80 \pm 0.07$ with higher values associated with maritime air masses. 
Sensitivity tests using simple cloud models as well as comparisons with in situ aircraft measurements indicate that the retrieved value of $r_{\text {eff }}$ is typically within $85 \%-90 \%$ of its value at cloud top (e.g., Nakajima and King 1990; Nakajima and Nakajima 1995). Making the approximation that this retrieved value, $r_{\text {eff,sat }}$, is equal to $r_{\text {eff }}(H)$ and substituting $k^{1 / 3} r_{\text {vol }}(H)$ for $r_{\text {eff }}$ in (A3) gives

$$
\begin{aligned}
\tau & =a_{1}^{-1} N_{\mathrm{sat}}^{2} r_{\mathrm{eff}}^{5}, \\
a_{1} & =\frac{5 A}{3 \pi Q_{\mathrm{ext}}},
\end{aligned}
$$

with $N_{\text {sat }}=k N / \sqrt{\beta}$.
The relationship for lwp is calculated similarly, substituting (A2) into (A1e), integrating, and using the relationship between $r_{\mathrm{vol}}, r_{\text {eff }}$, and $w$ at cloud top to obtain

$$
\begin{aligned}
\operatorname{lwp} & =a_{0} \tau r_{\mathrm{eff}}, \\
a_{0} & =\frac{10 \rho_{w}}{9 Q_{\mathrm{ext}}} .
\end{aligned}
$$

Values for $N_{\text {sat }}$ and lwp in this paper are calculated assuming $Q_{\text {ext }}=2$ and $C_{w}=C_{w}($ temperature $=285 \mathrm{~K})$ $=2 \times 10^{-3} \mathrm{~g} \mathrm{~m}^{-3} \mathrm{~m}^{-1} ; 285 \mathrm{~K}$ is a representative cloudbase temperature for both the northeastern Pacific and SOCEX clouds.

\begin{tabular}{|c|c|c|c|c|c|}
\hline Scene No. & Date/orbit ID & Lat $\left({ }^{\circ} \mathrm{N}\right)$ & Long $\left({ }^{\circ} \mathrm{W}\right)$ & Zenith $\left({ }^{\circ}\right)$ & View $\left({ }^{\circ}\right)$ \\
\hline 1 & $87 / 07 / 16$ N10-4294 & 35.03 & -132.46 & 54.6 & 5.0 \\
\hline 2 & $87 / 07 / 09$ N10-4194 & 28.66 & -124.62 & 50.8 & 7.5 \\
\hline 3 & $87 / 07 / 12$ N10-4237 & 34.89 & -129.88 & 54.9 & 14.5 \\
\hline 4 & 94/07/17 N11-29943 & 35.38 & -127.93 & 51.2 & 24.8 \\
\hline 5 & $87 / 06 / 23$ N10-3951 & 30.61 & -131.16 & 64.8 & 14.6 \\
\hline 6 & 94/07/16 N11-29929 & 24.40 & -121.11 & 64.8 & 14.5 \\
\hline 7 & $87 / 06 / 23$ N10-3951 & 38.40 & -128.62 & 50.1 & 13.5 \\
\hline 8 & $87 / 07 / 14$ N10-4265 & 28.19 & -117.65 & 54.3 & 29.7 \\
\hline 9 & $95 / 06 / 15$ N12-21220 & 24.86 & -131.89 & 63.0 & 6.8 \\
\hline 10 & 87/07/14 N09-13324 & 29.23 & -126.94 & 36.1 & 5.4 \\
\hline 11 & $94 / 07 / 17$ N11-29943 & 38.27 & -124.20 & 57.2 & 4.0 \\
\hline 12 & 94/07/17 N11-29943 & 37.93 & -124.93 & 57.7 & 5.2 \\
\hline 13 & 87/07/14 N09-13324 & 33.84 & -123.84 & 39.7 & 12.3 \\
\hline 14 & $87 / 07 / 10$ N10-4208 & 30.60 & -121.00 & 39.9 & 28.6 \\
\hline 15 & $94 / 07 / 16$ N11-29929 & 23.63 & -126.02 & 60.5 & 5.0 \\
\hline 16 & $87 / 07 / 12$ N10-4237 & 33.53 & -124.71 & 50.6 & 20.4 \\
\hline 17 & $87 / 07 / 16$ N10-4294 & 32.11 & -133.30 & 55.4 & 12.0 \\
\hline 18 & $94 / 07 / 12$ N11-29802 & 34.89 & -129.88 & 58.1 & 21.6 \\
\hline 19 & $87 / 07 / 31$ N10-4507 & 29.29 & -126.12 & 60.7 & 7.9 \\
\hline 20 & $94 / 06 / 23$ N11-29802 & 25.54 & -128.83 & 55.3 & 34.4 \\
\hline 21 & $94 / 07 / 16$ N11-29830 & 40.32 & -132.12 & 56.1 & 48.0 \\
\hline 22 & $94 / 06 / 23$ N11-29717 & 38.20 & -132.30 & 59.9 & 48.0 \\
\hline 23 & 95/07/14 N14-20266 & 34.11 & -124.34 & 51.3 & 45.5 \\
\hline 24 & $87 / 07 / 07$ N10-4166 & 29.62 & -124.81 & 48.3 & 11.9 \\
\hline 25 & $87 / 07 / 04$ N10-4123 & 31.52 & -121.42 & 52.9 & 10.0 \\
\hline
\end{tabular}

\section{APPENDIX B}

\section{Satellite Scene Locations}

TABLE B1. Year/month/day and satellite number and orbit for the images of Fig. 1.

TABLE B2. SOCEX flight missions and coordinated satellite overpasses.

\begin{tabular}{ccclc}
\hline \hline $\begin{array}{c}\text { Flight } \\
\text { No. }\end{array}$ & $\begin{array}{c}\text { Day in } \\
1995\end{array}$ & $\begin{array}{c}\text { Flight time } \\
\text { (local) }\end{array}$ & \multicolumn{1}{c}{$\begin{array}{c}\text { Satellite } \\
\text { orbit No. }\end{array}$} & $\begin{array}{c}\text { Satellite } \\
\text { time } \\
\text { (local) }\end{array}$ \\
\hline 6 & $1 \mathrm{Feb}$ & $0941-1410$ & NOAA-9 52266 & 1007 \\
7 & $1 \mathrm{Feb}$ & $1537-1908$ & NOAA -1400462 & 1549 \\
8 & $6 \mathrm{Feb}$ & $1511-1840$ & NOAA -1400532 & 1455 \\
9 & $8 \mathrm{Feb}$ & $0945-1330$ & NOAA -952365 & 1017 \\
10 & $8 \mathrm{Feb}$ & $1515-1902$ & NOAA -1400561 & 1614 \\
11 & $9 \mathrm{Feb}$ & $1003-1348$ & NOAA-9 52379 & 1004 \\
\hline
\end{tabular}

\section{REFERENCES}

Austin, P., Y. Wang, R. Pincus, and V. Kujala, 1995: Precipitation in stratocumulus clouds: Observational and modeling results. $J$. Atmos. Sci., 52, 2329-2352.

Baumgardner, D., and M. Spowart, 1990: Evaluation of the Forward Scattering Spectrometer Probe. Part III: Time response and laser inhomogeneity limitations. J. Atmos. Oceanic Technol., 7, 666672.

Boers, R., and R. M. Mitchell, 1994: Absorption feedback in stratocumulus clouds: Influence on cloud-top albedo. Tellus, 46A, $229-241$.

_ , J. Jensen, P. Krummel, and H. Gerber, 1996: Microphysical 
and short-wave radiative structure of wintertime stratocumulus over the southern ocean. Quart. J. Roy. Meteor. Soc., 122, 13071341.

Brenguier, J.-L., H. Pawlowska, L. Schüller, R. Preusker, J. Fischer, and Y. Fouquart, 2000: Radiative properties of boundary layer clouds: Droplet effective radius versus number concentration. $J$. Atmos. Sci., 57, 803-821.

Caughey, S. J., and C. K. Kitchen, 1984: Simultaneous measurements of the turbulent and microphysical structure of nocturnal stratocumulus cloud. Quart. J. Roy. Meteor. Soc., 110, 13-34.

Chambers, L., B. Wielicki, and K. Evans, 1997: Accuracy of the independent pixel approximation for satellite estimates of oceanic boundary layer cloud optical depth. J. Geophys. Res., 102, 1779-1794.

Coakley, J. A., and F. P. Bretherton, 1982: Cloud cover from highresolution scanner data: Detecting and allowing for partially filled fields of view. J. Geophys. Res., 87, 4917-4932.

Greenwald, T. J., and S. A. Christopher, 1999: Daytime variation of marine stratocumulus microphysical properties as observed from geostationary satellite. Geophys. Res. Lett., 26, 1723-1726.

- - - J. Chou, and J. C. Liljegren, 1999: Intercomparison of cloud liquid water path derived from the GOES 9 imager and ground based microwave radiometers for continental stratocumulus. J. Geophys. Res., 104, 9251-9260.

Han, Q., W. Rossow, and A. Lacis, 1994: Near-global survey of effective droplet radii in liquid water clouds using ISCCP data. J. Climate, 7, 465-497.

- _ — R. Welch, A. White, and J. Chou, 1995: Validation of satellite retrievals of cloud microphysics and liquid water path using observations from FIRE. J. Atmos. Sci., 52, 4183-4195.

— $—$ - J. Chou, and R. M. Welch, 1998a: Global survey of the relationships of cloud albedo and liquid water path with droplet size using ISCCP. J. Climate, 11, 1516-1528.

$\_,-, \ldots$, and —_, 1998b: Global variation of column droplet concentration in low-level clouds. Geophys. Res. Lett., 25 , 1419-1422.

Hartmann, D., M. Ockert-Bell, and M. Michelsen, 1992: The effect of cloud type on earth's energy balance: Global analysis. J. Climate, 5, 1281-1304.

Isaaks, E., and R. Srivastava, 1989: An Introduction to Applied Geostatistics. Oxford University Press, $561 \mathrm{pp}$.

Jansson, M., 1985: A comparison of detransformed logarithmic regressions and power function regressions. Geogr. Ann., 67A, $61-70$.

Kaufman, Y. J., and B. N. Holben, 1993: Calibration of the AVHRR visible and near-IR bands by atmospheric scattering, ocean glint and desert. Int. J. Remote Sens., 14, 21-52.

Khairoutdinov, M. F., and Y. L. Kogan, 1999: A large eddy simulation model with explicit microphysics: Validation against aircraft observations of a stratocumulus-topped bounary layer. J. Atmos. Sci., 56, 2115-2131.

Kneizys, F., E. Shettle, L. Abreu, J. C. Chetwynd, Jr., S. Anderson, W. Gallery, J. Selby, and S. Clough, 1988: Users guide to LOWTRAN-7. Air Force Geophysics Laboratory Tech. Rep. AFGLTR-88-0177, 137 pp.

Lohmann, U., and J. Feichter, 1997: The atmospheric sulfur cycle in ECHAM-4 and its impact on the shortwave radiation. J. Geophys. Res., 102, 13 685-13 700.

Martin, G. M., D. W. Johnson, and A. Spice, 1994: The measurement and parametrisation of effective radius in warm stratocumulus clouds. J. Atmos. Sci., 51, 1823-1842.

Nakajima, Ta., and Te. Nakajima, 1995: Wide-area determination of cloud microphysical properties from NOAA AVHRR measurements for FIRE and ASTEX regions. J. Atmos. Sci., 52, 40434059.

Nakajima, Te., and M. King, 1990: Determination of the optical thickness and effective particle radius of clouds from reflected radiation measurements. Part I: Theory. J. Atmos. Sci., 47, 18781892.

_ - , J. Spinhirne, and L. Radke, 1991: Determination of the optical thickness and effective particle radius of clouds from reflected radiation measurements. Part II: Marine stratocumulus observations. J. Atmos. Sci., 48, 728-750.

Nicholls, S., 1984: The dynamics of stratocumulus: Aircraft observations and comparisons with mixed layer models. Quart. J. Roy. Meteor. Soc., 110, 783-820.

Pincus, R., M. Szczodrak, P. Austin, and J. Gu, 1995: Precision and accuracy in satellite optical depth estimates. J. Climate, 8, 14531462.

Platnick, S., and F. Valero, 1995: A validation of satellite cloud retrieval during ASTEX. J. Atmos. Sci., 52, 2985-3001.

Pontikis, C., 1993: Parameterization of the cloud optical thickness: Influence of clear air entrainment. Geophys. Res. Lett., 20, 26552658.

Szczodrak, M., 1998: Variability of cloud optical depth and cloud droplet effective radius in layer clouds: Satellite based analysis. $\mathrm{Ph} . \mathrm{D}$. thesis, University of British Columbia, Vancouver, BC, Canada, 213 pp.

Wang, S., and Q. Wang, 1994: Roles of drizzle in a one-dimensional third-order turbulence closure model of the nocturnal stratustopped marine boundary layer. J. Atmos. Sci., 51, 1559-1576.

Zuidema, P., and D. Hartmann, 1995: Satellite determination of stratus cloud microphysical properties. J. Climate, 8, 1638-1657. 